was studied under conditions in which the specific activity of labelled glucose in the hæmolymph, where it is in equilibrium with trehalose, approximated to that in the gut lumen. This was achieved by injecting sufficient labelled glucose into the hæmolymph so that, when it had come into equilibrium with the trehalose, the radioactivity of the glucose was similar to that in the gut lumen. Results obtained under these conditions have been compared with those for the uptake of labelled glucose by insects initially containing no radioactive material in the hæmolymph.

It has been found that the presence of labelled glucose in the hæmolymph greatly reduced the percentage absorption of the labelled glucose from the gut lumen when the concentration there was low. This effect decreased with increasing concentration and became negligibly small when a concentration of about $0.01 M$ was reached in the lumen. These results are summarized in Fig. 1. The absolute amount of labelled glucose (in $\mu \mathrm{gm}$.) absorbed from the lumen of the cæca can be calculated from the results in Fig. 1, from the fact that the initial volume of the cæca contents averaged $0.039 \pm 0.009 \mathrm{ml}$. (Fig. 2). The net glucose absorption from the mid-gut cæces is thus represented by the continuous line in Fig. 2. Thus at relatively low concentrations much of the uptake of the labelled glucose molecules was due to exchange with that in the hæmolymph. With increasing concentration the proportion exchanging with that in the hæmolymph became progressively smaller.

It is clear, therefore, that the postulated facilitated diffusion mechanism, involving the conversion to trehalose, can only produce a net glucose absorption when the concentration in the gut lumen exceeds the very low level in the hæmolymph. At very low concentrations some additional mechanism must be postulated to explain any net glucose absorption which may be observed. This topic will be considered more fully in a detailed account of this work to be published elsewhere.

Agricultural Research Council

$$
\text { J. E. TREhERNE }
$$

Unit of Insect Physiology,

Department of Zoology,

University of Cambridge.

March 3.

${ }^{1}$ Treherne, J. E., J. Exp. Biol. (in the press).

'Danielli, J. F., in "Recent Developments in Cell Physiology", ed. J. A, Kitching (Butterworth, London, 1954).

Howden, G. F., and Kilby, B. A., Chem. and Ind., 1455 (1956).

\section{Role of Glycerol in producing Abnormally Low Supercooling and Freezing Points in an Insect, Bracon cephi (Gahan)}

MosT insects have freezing points only a degree or two below $0^{\circ} \mathrm{C}$., but can be supercooled to much lower temperatures ${ }^{1}$. When supercooling points as low as $\rightarrow 47^{\circ} \mathrm{C}$. were recorded $\mathrm{d}^{2}$ for overwintering larvæ of Bracon cephi (Gahan), a parasite of the wheat stem sawfly, Cephus cinctus Nort., abnormally low freezing points were expected because water is highly unlikely to supercool ${ }^{3}$ more than $40 \mathrm{deg}$. C. Freezing points (determined as melting points ${ }^{1}$ ) of the hæmolymph of these larvæ ranged from $-7^{\circ}$ to $-17^{\circ} \mathrm{C}$. These values were closely related to the corresponding supercooling points of the intact insects, which were 28-30 deg. C. lower. This uniform amount of supercooling conforms with Lusena's findings ${ }^{4}$ with aqueous solutions of sodium chloride and glycerol.

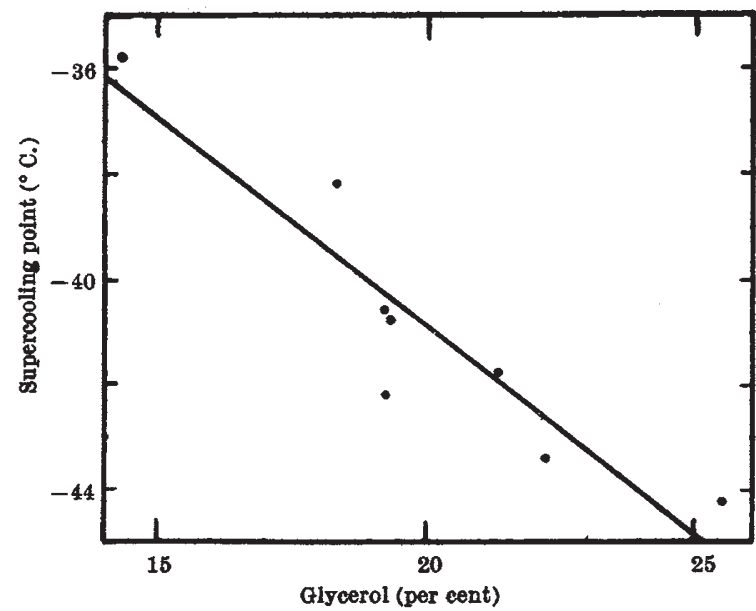

Fig. 1. Relation of glycerol contents of larve of Bracon cephi (Gahan) to their supercooling points. Regression line calculated

In an attempt to account for the very low freezing points found in $B$. cephi larvæ, the amounts of glycerol were estimated by a chromatographic method ${ }^{5}$ in samples of ten larvæ each. Three chromatograms were run for each sample and two estimates based on different concentrations and glycerol standards were obtained from each chromatogram. The mean glycerol content of eight samples was 20.0 per cent, calculated as percentage of glycerol plus water content. Alone, such a solution would freeze at $-4 \cdot 8^{\circ} \mathrm{C}$. The excess depression observed in insects is partly due to and may be fully accounted for by salts, sugars, amino-acids and neutral solutes other than glycerol. However, Fig. 1 shows a supercooling-point depression (and consequently an approximately equal freezing- or melting-point depression) of $7.9 \mathrm{deg}$. C. for a 10 per cent increase in glycerol (from 15 to 25 per cent). In corresponding pure glycerol solutions the depression for this range is $4 \cdot 1 \mathrm{deg}$. C. The difference can be accounted for by glycerol if it binds a considerable portion of the insect's water content, thereby concentrating other solutes. The alternative is a high titre of other freezing-point depressants.

\section{R. W. SALT}

Science Service Laboratory, Lethbridge, Alberta. Feb. 7.

${ }^{1}$ Salt, R. W., Canad. J. Zool., 34, 1 (1956).

- Salt, R. W., Canad. J. Zool., 84, 288 (1956).

${ }^{8}$ Mason, B. J., Sei. Progr., 44, 479 (1956).

'Lusena, C. V., Arch. Biochem. Biophys., 57, 277 (1955).

'Salt, R. W., Canad. Ent., 89, 491 (1957).

\section{Volatile Amines of Herring Flesh}

Gas chromatography ${ }^{1,2}$ affords a rapid method for the specific identification and estimation of the volatile amines which are produced in fish flesh. In the experiments to be described, amines were quantitatively extracted from the flesh of herring (Clupea harengus) with aqueous 10 per cent trichloracetio acid solution and steam distilled at $p H 10$ into excess dilute hydrochloric acid solution. The distillate was concentrated under reduced pressure, and finslly freeze-dried. The resulting residue of amine hydrochlorides was dissolved in a suitable volume of water and applied to the gas chromatography column in 